\title{
Ozone and water vapor measurements by Raman lidar in the planetary boundary layer: error sources and field measurements
}

Benoît Lazzarotto ${ }^{a}$, Max Frioud ${ }^{b}$, Gilles Larchevêque ${ }^{a}$, Valentin Mitev ${ }^{b}$, Philippe Quaglia ${ }^{a}$, Valentin Simeonov ${ }^{\mathrm{a}}$, Anne Thompson ${ }^{c}$, Hubert Van den Bergh ${ }^{\mathrm{a}}$ and Bertrand Calpini ${ }^{{ }^{*}}$

${ }^{\text {a }}$ Laboratory for air pollution / Lidar group. EPFL, Swiss Federal Institute of Technology CH-1015. LAUSANNE. SWITZERLANE ...

\author{
${ }^{b}$ Observatory of Neuchatel, \\ CH-2000. NEUCHATEL. SWITZERLAND
}

${ }^{c}$ NASA / GSFC

Code 916, Grennbelt MD 20771. USA

" Corresponding author: e-mail bertrand.calpini@epfl.ch , tel : (++41) (021) 6936185 


\section{Rationale}

Why do we need time series of ozone and water vapor profile at low altitude?

The degradation of air quality is a very serious environmental problem that affects urban and industrial areas worldwide. Air pollution injures human health and ecosystems, diminishes crop yield, and spoils patrimony and materials. The phenomena involved in air pollution are very complex. Once emitted into the atmosphere, (primary) pollutants are transported, dispersed, transformed by gas/solid phase change and chemical reaction, and finally removed by dry and wet deposition.

Most challenging is the fact that the health and environmental impacts of secondary pollutants (formed in the atmosphere) are frequently more severe than those of their precursors (primary pollutants). This is the case of ozone and other photochemical pollutants, such as peroxyacetil nitrate (PAN) and secondary particles, produced in the atmosphere by the photo-oxidation volatile organic compounds (VOC) catalyzed by nitrogen oxides $\left(\mathrm{NO}_{\mathrm{X}}\right)$. Photochemical air pollution is a complex science because of the non-linearity of its response to changes in primary emission (see for example Finlayson-Pitts, 1999). ${ }^{1}$

Three Dimensional air quality models are used as the most powerful tool for identifying effective strategies to improve air quality. With the meso-scale Eulerian chemical transport model developed at EPFL we may simulate pollutant dynamics over region like Athens, Milan, or regions with high traffic loads in Switzerland and provide technical guidance to air quality management agencies. ${ }^{2-4}$ The model resolution is of the order of $1 \mathrm{~km}$ on the horizontal scale, with a vertical resolution of some tens of meters for the lowest layer of the model, up to $500 \mathrm{~m}$ for the top layer, and a total height of $5 \mathrm{~km}$ above ground level. The domain size is typically $100 \times 100 \mathrm{~km}$. Before the model results can be used with confidence, they must be validated against field measurements with similar spatial and time resolution. Most of the time, an air quality network in densely urbanized region is builtupon a set of ground based stations equipped with point detectors. Trace gas measurements are often influenced by local sources and thus are not representative of the averaged concentrations over the typical grid size of the model. On the contrary, tropospheric lidar measurements are based on an integrated optical path of typically 50 to 500 meters depending upon the trace gas species. This spatial resolution is in ideal agreement with the model one and may help retrieving essential information for the model validation among which the ozone or water vapor vertical profile.

Ozone as a secondary pollutant is an ideal species to compare with its predicted values obtained by the model. Because ozone is "produced" in the model by photochemical reactions and transport effects, a 
correct the water vapor Raman return for tropospheric ozone attenuation. ${ }^{14}$ The same principle was also successfully applied in the stratosphere. ${ }^{15}$

Here we apply these earlier concepts to the development of an operational lidar instrument, for day and nighttime measurements, and for time series of some days to follow the vertical dynamics and time evolution of an air pollution episode. Section 2 of this paper presents a model estimate of the determination of the critical system parameters. Section 3 defines the experimental setup and Section 4 gives some typical results obtained for different time series of ozone and water concentration and compared by other means.

\section{Raman lidar: principle and predicted error sources}

Figure 1 shows a schematic of the Raman lidar system. The ozone retrieve-is-based only on the $\mathrm{N}_{2}$ and $\mathrm{O}_{2}$ channels. For the water vapor retrieve, we may use either $\mathrm{N}_{2} \& \mathrm{H}_{2} \mathrm{O}$ \% ${ }_{2}$ \& $\mathrm{H}_{2} \mathrm{O}$ pairs of channels. To each of the three Raman-shifted wavelengths corresponds a lidar equation:

Where the index $X$ stands for $\mathrm{O}_{2}, \mathrm{~N}_{2}$ or $\mathrm{H}_{2} \mathrm{O}$,

in [W] the Raman lidar power backscattered from species $X$ at Raman-shifted wavelength and distance $R$, in [W] the laser emitted power at wavelength $\lambda_{L}, K_{X}$ the instrument constant at Raman-shifted wavelength $\quad, O(R)$ in $\left[\mathrm{cm}^{2}\right]$ the telescope active surface area, $n_{X}(R)$ in $\left[\# \mathrm{molec} / \mathrm{cm}^{3}\right]$ the molecular density of species $X$ at distance $R$, $n$

in $\left[\mathrm{cm}^{2} / \mathrm{strad}\right]$ the Raman backscattering cross-section for species $X$ (with $d \Omega$ the solid angle of detection), $\alpha_{X}(r)$ and $\alpha_{L}(r)$ in $\left[\mathrm{cm}^{-1}\right]$ the atmospheric extinction coefficient at Ramanshifted wavelength and respectively at the pump laser wavelength, $\sigma_{X}(r)$ and $\sigma_{L}(r)$ in $\left[\mathrm{cm}^{2} / \#\right.$ molec] the ozone absorption cross section at Raman-shifted wavelength and respectively at the pump laser wavelength. The ozone concentration $\%$ in $\left[\#\right.$ molec $\left./ \mathrm{cm}^{3}\right]$ can be calculated from the $\mathrm{N}_{2}$ and $\mathrm{O}_{2}$ Raman signals using a modified DIAL equation in the following form: n. 
where $n_{t a r}^{m a t}$ is the air molecular density. As the numerator in Eq. (4) is also directly depending upon the air density. the result $\Delta^{\mathrm{mol}}$ is given as an altitude independent value in this formalism. It corresponds to a correction of about 3 ppbv.

Let us now add an homogeneous aerosol layer characterized by two variables in the model: the total lidar ratio $e$ defined as the total extinction $\alpha_{\text {total }}$ divided by the total backscattering $\beta_{\text {total }}$, and the backscattering ratio $b$ defined as the total backscattering $\beta_{\text {total divided by the molecular }}$ backscattering $\beta_{\mathrm{g}}$. With the assumption of atmospheric molecular species with mean diameter much smaller than the laser wavelength, the molecular backscattering $\beta_{\mathrm{g}}$ is defined following Collis and Russell ${ }^{16}$ by:
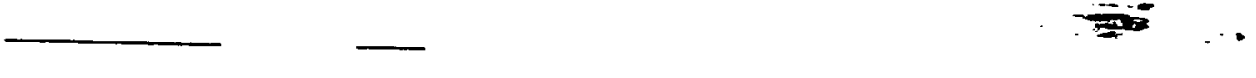

Where the molecular backscattering $\beta_{g}$ is in $\left[\mathrm{m}^{-1} \mathrm{sr}^{-1}\right]$, the laser wavelength $\lambda_{L}$ in [nm] and the air density $n_{\text {air }}^{\text {mol }}$ in $\left[\mathrm{m}^{-3}\right]$. One may also assume a power-law for the wavelength-dependency of the extinction due to Mie particles $\left(\alpha^{\text {aer }}-\lambda\right)$ following previous work ${ }^{17}$ where $\gamma$ was shown to range from $\gamma$ $\in[-1,-0.5]$. With $\gamma=-1$ the following estimation of the aerosol correction $\Delta^{\text {aer }}$ to the ozone concentration is obtained:

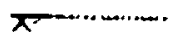

where $c^{R a y l}=\frac{8 \pi}{3}$ is the molecular lidar ratio (Rayleigh contribution). With the parameters stated in Table 1, this yields the following aerosol contribution to the ozone correction:

Here we used for the molecular density and the water vapor content a model atmosphere defined in (AFGL-TR-86-0110, model $\left.n^{\circ} 3\right)^{18}$ with "midlatitude winter" conditions to compare with experimental results presented below. The total extinction and backscattering coefficients were defined for the $4^{\text {th }}$ Harmonic of a Nd:YAG laser source at $266 \mathrm{~nm}$ taking into account the effect of a constant aerosol vertical profile. In order to simulate the most severe aerosol conditions, the aerosol optical properties were "tuned" to their maximum acceptable (or worse) values for $e$ and $b$ of respectively 40 and 1.8 . With these extreme aerosol conditions, the ozone shift $\Delta^{\text {aer }}$ due to the aerosol for this Raman DIAL 
soundings) to correct for its differential absorption effect using in this case solely Eq. (3). This solution will also be presented in the next Section.

The predicted ozone absorption effect on the water vapor measurements is shown in Fig. 2 for a model atmosphere with different constant values of the ozone vertical profile, an homogeneous aerosol layer with $(e=40 ; b=1.8)$ and the lidar experimental inputs stated in Table 2 that will be discussed in the next Section. Note that the vertical range starts only from $200 \mathrm{~m}$ above ground level at the altitude where a full overlap between the laser beam and the telescope field of view is achieved. The shift $\Delta \mathrm{H}_{2} \mathrm{O}$ on the water vapor mixing ratio retrieval on the horizontal axis is obtained simply by considering Eq. (3) with and without the "ozone" correction term. For example with a constant vertical profile of $40 \mathrm{ppb}$ of ozone, the shift at $600 \mathrm{~m}$ is already higher than $20 \%$ as compared with the absolute water values in the model atmosphere. This predicted effect is enhanced by the presence of homogeneous aerosol layer and its contribution to the aerosol extinction term considered in Eq. (3). Note that the ozone absorption and the aerosol extinction terms are both values that are integrated over the altitude range in Eq. (3). This is the reason why the shift in the water mixing ratio increases versus the range. This model result underlines that a Raman lidar measurement of the water vapor mixing ratio in the atmosphere cannot be adequately performed without taking care of the ozone absorption effect as well.

\section{Statistical (quantum) noise}

The statistical noise is a major perturbation in Raman lidar measurements ${ }^{17}$ due to the low Raman crosssection, typically four orders of magnitude lower than the elastic cross-section, and therefore due to the low Raman signal level. The statistical noise has been modeled following the Poisson statistics with the parameters defined in Table 2. In this case the model study was performed in a purely molecular atmosphere (no aerosol layer). Based on typical experimental values we estimate a number of photoelectrons per pulse at the photo-cathode, from a distance of $200 \mathrm{~m}$ and for-one ADC channel of $7.5 \mathrm{~m}$ resolution, of some hundreds for both $\mathrm{N}_{2}$ and $\mathrm{O}_{2}$ Raman lidar signals and some counts for $\mathrm{H}_{2} \mathrm{O}$. This model simulation of the statistical noise is based on series of 100 runs for each similar initial condition. From these series of runs the standard deviation with respect to the mean value is obtained and reported in Fig. 3 versus the range.

Figure 3(a) shows the ozone standard deviation due to the effect of the statistical noise on the retrieved ozone concentration for three profiles with constant ozone concentrations of respectively 0,40 and 80 ppb. These results are achieved averaging over 5 files of 4000 laser shots as defined in Table 2. With a sampling rate of $20 \mathrm{MHz}$ the ultimate range resolution is $7.5 \mathrm{~m}$. Such short optical integration path 
Let us consider first the cross-talk between $\mathrm{N}_{2} \& \mathrm{O}_{2}$ Raman signals biasing the ozone retrieve and the cross-talk between $\mathrm{H}_{2} \mathrm{O}$ and $\mathrm{O}_{2}$ Raman signals biasing the water vapor retrieve. Different model runs were performed for cross-talks ranging from $10^{-6}$ to $10^{-3}$ with a model atmosphere with constant ozone vertical profile (80ppb) and an aerosol layer with $b=1.8$ and $e=40$. The model results show very small effect due to this optical effect. The associated errors on ozone were always lower than $0.3 \mathrm{ppb}$ while they remained below $0.01 \mathrm{gH}_{2} \mathrm{O} / \mathrm{kg}$ dry air for the water vapor in the worse case. As an example of these simulation runs Fig. 4 shows the cross-talk effect due to the Raman shifted $\mathrm{O}_{2}$ signal on $\mathrm{H}_{2} \mathrm{O}$ versus the altitude range. Since the $\mathrm{H}_{2} \mathrm{O}$ Raman signal has by far the weakest signal intensity as compared with the two other Raman signals mainly because of its comparatively much lower concentration one may expect the strongest (or worst) effect of the cross-talk in this case. The predicted shift in the water vapor mixing ratio retrieval $\Delta \mathrm{H}_{2} \mathrm{O}$ presented in Fig. on the horizontal axis is the difference between the water vapor retrieval without any cross-talk effect versus the same retrieval biased by the cross-talk of the $\mathrm{O}_{2}$ signal on $\mathrm{H}_{2} \mathrm{O}$. As these runs are performed in an atmosphere with very high aerosol load and a constant $80 \mathrm{ppb}$ of ozone the simulation shows that the largest cross talk effect are expected at long range where the signal to noise ratio is the weakest. For a cross-talk of $10^{-3}$ at a range of $200 \mathrm{~m}$ the expected shift is about $-10^{-3} \mathrm{~g} / \mathrm{kg}$ dry air (negative correction) and it reaches a value of $10^{-2}$ at 1'200 $\mathrm{m}$ or an effect higher by typically one order of magnitude. This simulation is performed with a constant detection efficiency versus the range. In this sense the effect of an incomplete detection of the Raman signal at short distance where the probed air volume image in the grating polychromator is the largest is not taken into account.

For the cross-talk between the elastic backscattered light and the Raman channels, one may expect a stronger effect since the elastic backscattered cross section is up to four orders of magnitude higher than the Raman cross section. This aspect is addressed in detail in the experimental layout presented in Section 3. In order to prevent such strong optical interference, additional filters are set at the entrance of the polychromator with a rejection ratio between the $266 \mathrm{~nm}$ light and the other Raman channels of more than five orders of magnitude. Model runs were performed with cross-talk values ranging from $10^{\circ}$ ${ }^{9}$ to $10^{-6}$ between the elastic backscattered light and any of the different Raman channels. The associated errors due to the elastic cross talk on ozone remained always below $0.15 \mathrm{ppb}$ and for the water vapor below $0.1 \mathrm{gH}_{2} \mathrm{O} / \mathrm{kg}$ dry air in the worse case.

In summary, the two types of optical cross-talk have negligible effect if the wavelength separation unit allows achieving a cross-talk level lower than $10^{-3}$ for two adjacent Raman channels, and lower than $10^{-}$ 
Systematic errors such as interference with other trace gas species in the atmosphere or the spectral stability of the laser source must also be considered.

In Eq. (2) the ozone absorption cross section was the only absorbing species taken into account. The DIAL technique is sensitive to the influence of any other absorbing trace-gas species in the wavelength region used. The main interference in the $\mathrm{UV}$ for tropospheric measurements is $\mathrm{SO}_{2}$ and $\mathrm{NO}_{2}$. Table 1 gives also their respective absorption cross-section as compared with the ozone one for the three Raman wavelengths considered in this study. The ozone differential absorption cross-section is linearly depending upon the ozone retrieval in Eq. (2). Thus, any interfering gas (IG) will induce a systematic error on the ozone retrieval $\mathrm{\Delta O}_{3}$ in the form of the following ratio:

$$
\Delta O_{3}=-\frac{\left(\sigma_{I G}\left(\lambda_{o f f}\right)-\sigma_{I G}\left(\lambda_{o n}\right)\right) N_{I G}}{\left(\sigma_{O 3}\left(\lambda_{o f f}\right)-\sigma_{O 3}\left(\lambda_{o n}\right)\right)}
$$

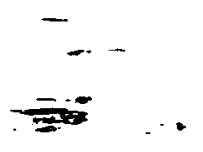

where $N_{I G}$ is the interfering gas concentration, and $\lambda_{o f f}$ and $\lambda_{o n}$ are the respectively "off" and "on" resonance wavelengths in the DIAL formalism. The ratio of the differential absorption cross-section for $\mathrm{NO}_{2}$ versus $\mathrm{O}_{3}$ is $-7.6110^{-3}$ while it reaches a value of $-10^{-1}$ for $\mathrm{SO}_{2}$. In other words for a concentration of $\mathrm{NO}_{2}=100 \mathrm{ppb}$ the systematic error $\Delta \mathrm{O}_{3}$ on the ozone retrieval is less than $-1 \mathrm{ppb}$ while for $\mathrm{SO}_{2}=100$ $\mathrm{ppb}$ it would be $-10 \mathrm{ppb}$ of ozone. One should point out that such error sources affect not only the Raman DIAL but also any elastic DIAL measurements while on the other hand they remain relatively small in most case studies.

For the water vapor mixing ratio retrieval in Eq. (3) an "ozone correction" term was considered. This term will similarly be affected by the presence of additional trace gas species absorbing at the wavelengths considered for the Raman water vapor retrieval. For $\mathrm{NO}_{2}$ absorbing at the Raman shifted $\mathrm{H}_{2} \mathrm{O}$ and $\mathrm{N}_{2}$ wavelengths the ratio defined in Eq. (11) of its differential cross section with respect to the ozone differential absorption corresponds to $-2.910^{-2}$, and respectively fer: $\mathrm{SO}_{2}$ the same ratio is -1.17 $10^{-2}$. Thus, this interference may be for both interfering species considered as negligible. Nevertheless since they appear in the integral term in Eq. (3) they will play a more significant role for a longer range of measurements.

The spectral stability of the laser source may as well be a source of systematic error since a shift in the emitted wavelength will induce a displacement of the lidar signal image at the output of the polychromator. Hence the specified spectral stability of the laser source by the manufacturer is $1 \mathrm{~cm}^{-1}$ or a wavelength shift of less than $0.015 \mathrm{~nm}$ at $266 \mathrm{~nm}$. With a grating spectral resolution of $0.51 \mathrm{~nm} / \mathrm{mm}$ 
The Raman signals from $\mathrm{O}_{2}, \mathrm{~N}_{2}$ and $\mathrm{H}_{2} \mathrm{O}$ are detected simultaneously by three Hamamatsu H-5780-06 photosensor modules. Each of them is equipped with an optical diffuser and a short focal length lens to improve the spatial uniformity of the photosensor module. ${ }^{23}$ Thanks to a pulse duration of less than 0.65 ns achieved by such photodetectors, both analog and photon-counting detection modes are possible. The acquisition of the signals is performed using a Licel transient recorder that combines photon counting with a 12 bit $20 \mathrm{MHz}$ analog-to-digital converter. Raw data are averaged over 4000 shots and stored with the ultimate range resolution of $7.5 \mathrm{~m}$.

Experimental determination of the optical cross-talk

A careful analysis of the cross-talk measured in our experimental set-up was performed. Even though the three signals may affect each other, the influence of the $\mathrm{N}_{2}$ channel on the two others is stronger because it is the "central" wavelength and has the highest intensity levefir herefore, we measured the optical cross-talk caused by the $\mathrm{N}_{2}$ signal in the $\mathrm{O}_{2}$ and $\mathrm{H}_{2} \mathrm{O}$ channels. For the measurements we used light produced by stimulated Raman scattering of a $266 \mathrm{~nm}$ laser beam in 35 bar of nitrogen. A small fraction of its first Stokes at $283.6 \mathrm{~nm}$ was injected by an optical fiber into the lidar receiving telescope and the resulting crosstalk intensities in the oxygen and water vapor channels were measured by the respective PMTs. The intensity of the injected $283.6 \mathrm{~nm}$ light was chosen so that the resulting cross-talk intensities were well above the photo-detectors noise level. The light intensity in the nitrogen channel was measured using neutral density filters that attenuate the signal below the saturation level of the photo-detector. The cross-talk in the $\mathrm{O}_{2}$ and $\mathrm{H}_{2} \mathrm{O}$ channels was calculated as a ratio between the crosstalk intensity in the respective channel and the intensity in the $\mathrm{N}_{2}$ one, taking into account the relative photo-detectors sensitivity and the neutral density filters attenuation in the $\mathrm{N}_{2}$ channel. The measured cross-talk levels were respectively: $2.210^{-5}$ for $\mathrm{O}_{2} / \mathrm{N}_{2}$ and $5.210^{-5}$ for $\mathrm{H}_{2} \mathrm{O} / \mathrm{N}_{2}$. The previous simulation study showed that it is only with a cross-talk greater than $10^{-3}$ that a detectable bias on ozone or water vapor retrieve was expected. Our experimental cross-talk values were much lower, and low enough to neglect their influence. These values were also in good agreement with the stray light level stated by the polychromator manufacturer.

Care was also taken to "suppress" the residual elastic signal and to measure the degree of this suppression in the Raman channels. Since this degree is very high its direct measurement was impossible. Instead, the suppression of the elastic signal by the bandpass filters and the polychromator was measured separately. For the polychromator, the elastic backscatter light suppression was measured in a similar way than the one described above for the cross-talk among the Raman channels. this time 
signals was performed using a Labview based software with a real-time display of the preliminary results and post-treatment performed using Mathlab.

The time series in Fig. 6 shows the ozone vertical profile measured continuously over a period of time of 28 hours. Based on the statistical noise analysis presented in Section 2 of this paper, the lidar vertical resolution was set at $90 \mathrm{~m}$ and the time resolution at $30 \mathrm{~min}$. A gliding average was applied both on the altitude range and on the time scale. The white rectangle on Fig. 6 indicates the spatial range where ozone cannot be retrieved by lidar due to the uncompleted overlap between the laser beam and the telescope field of view. The value close to the ground are measured by the ozone point detector and presented here to show this nice correlation with the first altitude ozone retrieval by lidar at a height of $200 \mathrm{~m}$ agl.

In this time series, the ozone diurnal cycle was well seen, with higher vatiés during the period of high solar radiation, and lower values at nighttime. One should also note that this time series was taken in very humid conditions associated with formation of thin water cloud layers at night. But even so, essentially no data rejection in the ozone retrieval was needed, with the exception of some data between 22 and 24 hours local time at an altitude range higher than $500 \mathrm{~m}$ agl. Furthermore during this period of observation of more than one day, a strong variation of the height of the inversion layer was observed. The combined optical interference of cloud layers and the change in aerosol gradient due to the change in height of the top of the planetary boundary layer would have certainly affected or even made impossible any elastic DIAL ozone measurements in similar conditions. Such effects have been often reported ${ }^{9-10}$ but did not affect this ozone time series.

The water vapor time series following the data treatment in Eq. (10) with the three $\mathrm{N}_{2}, \mathrm{O}_{2}$, and $\mathrm{H}_{2} \mathrm{O}$ Raman signals is presented in Fig. 7. These measurements were taken simultaneously with the ozone measurements. As indicated previously the instrument constant $K_{X}$ being unknown an absolute profile of the water vapor mixing ratio in the air may only be obtained if an absolute reference is available at a given altitude. Since this is not the case here we used again the absolute water vapor concentration measured at the ground level as the reference value of the first altitude achieved by lidar, namely around $250 \mathrm{~m}$ agl. In a similar manner to the ozone time series in Fig. 6, the white rectangle in Fig. 7 covers the spatial range where the water vapor mixing ratio cannot be retrieved by lidar. But in this case the values measured close to the ground are equivalent to the reference values at $250 \mathrm{~m}$ agl. This means that the present water vapor mixing ratio time series must rather be regarded as a time series with relative 
be even worsen in case of atmospheric conditions with higher ozone concentration. Finally one should note that some negative values for $\Delta \mathrm{H}_{2} \mathrm{O}$ were obtained with magnitude down to $-0.1 \mathrm{~g} / \mathrm{Kg} \mathrm{dry}$ air in the worst cases. These values are directly associated with the limit of precision of our determination of the water vapor mixing ratio retrieval and are effectively slightly higher than the statistical error estimated by the model study.

Later in the year, the same lidar instrument was equipped on a movable platform and transported to Crete, Greece, to participate to the PAUR II program (Photochemical Activity and Ultraviolet Radiation Modulation Factors). ${ }^{24}$ While the system was most of the time operated in the ozone elastic DIAL mode, the chance for additional Raman water vapor measurements was offered for a short period of time with direct comparison with absolute water vapor profile measured by balloon. The balloon ozone and temperature profiles were determined with an electrochemical concitration cell ozone-sonde in combination with a RS-80/15Vis"la radio-sonde and a HumiCap humidity sensor. Procedures for sonde preparation and data acquisition are similar to those developed by NOAA/Climate Diagnostics and Monitoring Laboratories. ${ }^{25}$ One-second data were recorded and processed as described in Thompson et al. ${ }^{26}$ The balloon was launched from essentially the same place as the EPFL lidar trailer.

Figure 9 shows a comparison of the vertical water vapor profile obtained by Raman lidar and the balloon measurements. During this experiment the lidar system was only measuring the Raman $\mathrm{N}_{2}$ and $\mathrm{H}_{2} \mathrm{O}$ channels. Thus, we used directly the well-calibrated ozone data from the balloon to correct for the ozone interference effect on water vapor following Eq. (3). With the balloon measurement an absolute water vapor value was used to calibrate the Raman lidar data or namely to fix an absolute value to the lidar instrument constant $K_{X}$ at the first altitude where the water measurements were achievable by lidar. This altitude was $210 \mathrm{~m}$ above sea level (asl) where a full overlap between the laser beam and the telescope field of view was achieved. This absolute water vapor mixing ratio vertical profile retrieved by Raman lidar was obtained from averaging over 5 files of 4000 laser shots (total integration time of 30 minutes between 8 and $8.30 \mathrm{am}$ ) with a vertical resolution of $22.5 \mathrm{~m}$, and appeared to be in good agreement with the balloon data. The difference $\Delta \mathrm{H}_{2} \mathrm{O}$ reported in Fig. 9 between the water vapor obtained by lidar and by balloon was typically below $1 \mathrm{~g} \mathrm{H}_{2} \mathrm{O} / \mathrm{kg}$ dry air over the entire range, with the highest discrepancy observed at the height of the inversion layer. This transition layer was seen between $850-950 \mathrm{~m}$ asl in the balloon data, while in the case of the lidar data it was defined above $950 \mathrm{~m}$ asl. This difference may well be explained by the difference in time and air volume sampled by the two methods. In particular averaged values obtained by lidar over a period of 30 minutes were compared 
altitude or in more homogeneous aerosol conditions with the Raman DIAL method at low altitude will essentially help to cover an altitude range in full agreement with the model vertical grid resolution.

\section{Acknowledgements}

This work was supported by the Swiss National Science Foundation under contract $n^{\circ} 21-50861.97$. The balloon sounding was provided by NASA's TOMS project. The authors wish to thank the organizers of the PAUR II project for logistical support in Crete. 
11. A. J. Sedlacek and Mark D. Ray, "Raman DIAL: Application to areas characterized by varying aerosol burden," 19th ILRC, (1998).

12. S. H. Melfi. J.D. Lawrence Jr, and M.P. Mc Cormick, "Observation of Raman scattering by water vapor in the atmosphere," Appl. Phys. Lett., 15 , 295-297, (1969).

13. D. Renault, J.C. Pourny, and R. Capitini, "Daytime Raman-lidar measurements of water vapor," Optics Letter, 5 (6), 233 - 235, (1980).

14. D. Renault, and R. Capitini, "Boundary-Layer water vapor probing with a solar-blind Raman lidar: validation, meteorological observation and prospects," J. Atmos. Ocean. Tech. 5 (5), 585-601, (1988).

15. T. J. Mc Gee, M. Gross, R. Ferrare, W. Heaps, and U. Singh, "Raman DIAL measurements of stratospheric ozone in the presence of volcanic aerosols," J. Geophys. Fe"s. Let., 20, 955-958, (1983).

16. R. T. H. Collis, and P. B. Russell, "Lidar measurement of particles and gases by elastic backscattering and differential absorption," Laser monitoring of the atmosphere, E. D. Hinkley ed. , Springer-Verlag, 71-151, (1976).

17. J.A. Sunesson, "Differential absorption lidar system, for routine measurement of tropospheric ozone," Applied Optics, 33, 7045-7058, (1994).

18. G. P. Anderson, S. A. Clough, F. X. Kneizys, J. H. Chetwynd, and E. P. Shettle, "AFGL atmospheric constituent profiles ( 0 - 120 km )," Tech. Rep. AFGL-TR-86-0110, Air Force Geophys. Lab., Hascom Air Force Base, Mass., (1986).

19. P. B. Coates, "A theory of afterpulse formation in photomultipliers and the prepulse height distribution," J.Phys.D: Appl.Phys., 6, 1862-1869, (1973).

20. T. Antonioly, and P. Benetti, "Study of afterpulse effects in photomultipliers," Rev. Sci. Instrum., 54, 1777-1780, (1983).

21. P. B. Coates, "The origins of afterpulses in photomultipliers," J.Phys.D: Appl.Phys., 6, 1159-1166, (1973.)

22. B. Lazzarotto, V. Simeonov, P. Quaglia G. Larchevêque, H. van den Bergh, and B. Calpini, "A Raman Differential Absorption Lidar for Ozone and Water Vapor Measurement in the Lower Troposphere," Int. J. Env. Analytical Chem., 74, 255-261, (1999).

23. V. Simeonov, G. Larchevêque, P. Quaglia, H. van den Bergh, and B. Calpini, "The influence of the photomultiplier tube spatial uniformity on lidar signals," Applied Optics, 38, 5186-5190, (1999). 


\section{Figure captions}

Figure 1. Raman Lidar Scheme: The pulsed laser beam (PB) is emitted into the atmosphere via a beam expander $(x 3)$ and a set of right angle prisms. The elastically backscattered signal (EBS) and the Raman shifted backscattered signal (RBS) are collected by a $200 \mathrm{~mm}$ newtonian telescope, filtered at the entrance of a polychromator where they are spectrally resolved and injected into three photomultiplier tubes (PMT). The different PMT signals are stored in a transient recorder ( $\mathrm{ADC} 20 \mathrm{MHz} / 12$ bit and photon-counting) and a $\mathrm{PC}$ based computer unit allows for real time ozone and water vapor retrieval (raw data).

Figure 2. Ozone effect on water vapor retrieval: Predicted error on the water vapor mixing ratio retrieved by Raman lidar due to different ozone constant vertical profile and an homogeneous aerosol layer. The horizontal scale is the difference between thapor retrieval taking into account the ozone absorption and the same retrieval without ozone absorption.

Figure 3. Statistical Noise: Predicted standard deviation for ozone (a) and water vapor (b) Raman lidar retrieval due to the statistical noise (Poisson statistics) with the experimental parameters defined in Table 2.

Figure 4. Optical Cross-talk: Predicted error on water vapor Raman lidar retrieval due to the optical cross-talk between $\mathrm{H}_{2} \mathrm{O}$ and $\mathrm{O}_{2}$ Raman signals. The horizontal scale is the difference between the water vapor mixing ratio retrieval without cross-talk effect and the same retrieval bias by the cross-talk effect.

Figure 5. After Pulse Effect (APE): Predicted error on ozone (a) and water vapor (b) Raman lidar retrieval due to the APE. The horizontal scale is the difference between the ozone and the water vapor mixing ratio retrieval without APE compared with their respective retrieval bias by the APE. The model lidar signals are also shown versus their typical ADC voltage intensities ( $\log$ scale) with the Raman $\mathrm{O}_{2} \& \mathrm{~N}_{2}$ signals in the case of ozone and the Raman $\mathrm{H}_{2} \mathrm{O}$ and $\mathrm{O}_{2}$ signals for the water vapour mixing ratio.

Figure 6. Ozone Raman DIAL obtained in March 1999 for a time series of 28 hours. The ozone concentration measured at the ground are given by an UV absorption detector. They are measured by Raman DIAL from an altitude of $200 \mathrm{~m}$ agl and up to $700 \mathrm{~m}$ agl. The spatial resolution is $90 \mathrm{~m}$ and the time resolution 30 minutes.

Figure 7. Water vapor mixing ratio retrieved by Raman lidar: obtained in March 1999 for a time series of 24 hours with relative humidity measured at the ground. The latter values are also used at 
Table 1. Raman Shifted Optical Effects Induced by a $266 \mathrm{~nm}$ Laser Source in $\mathrm{O}_{2}, \mathrm{~N}_{2}$ and $\mathrm{H}_{2} \mathrm{O}$ and related major trace gas species absorption cross section

\begin{tabular}{|c|c|c|c|}
\hline Molecule & $\mathrm{O}_{2}$ & $\mathrm{~N}_{2}$ & $\mathrm{H}_{2} \mathrm{O}^{-}$ \\
\hline $\begin{array}{l}\text { Vibrational Raman shift } \\
{\left[\mathrm{cm}^{-1}\right]}\end{array}$ & 1555 & 2331 & $365 \mathrm{~F}$ \\
\hline $\begin{array}{l}\text { Corresponding Raman } \\
\text { wavelength } \\
{[\mathrm{nm}]}\end{array}$ & 277.5 & 283.6 & 294.6 \\
\hline $\begin{array}{l}\text { Molecular Raman scattering } \\
\text { cross-section. }{ }^{27} \\
{\left[10^{-30} \mathrm{~cm}^{2} / \text { strad] }\right.}\end{array}$ & 23.3 & 10.7 & 33.3 \\
\hline $\begin{array}{l}\text { Ozone absorption cross- } \\
\text { section. } 28 \\
{\left[10^{-20} \mathrm{~cm}^{2} / \text { molecule }\right]}\end{array}$ & 490.6 & 296.3 & 81.93 \\
\hline $\begin{array}{l}\mathrm{SO}_{2} \text { absorption cross- } \\
\text { section. }\end{array}$ & 64.4 & 84.5 & 90.8 \\
\hline $\begin{array}{l}\mathrm{NO}_{2} \text { absorption cross- } \\
\text { section. } \\
{\left[10^{-20} \mathrm{~cm}^{2} / \text { molecule }\right]}\end{array}$ & 4.82 & 6.30 & 9.98 \\
\hline
\end{tabular}



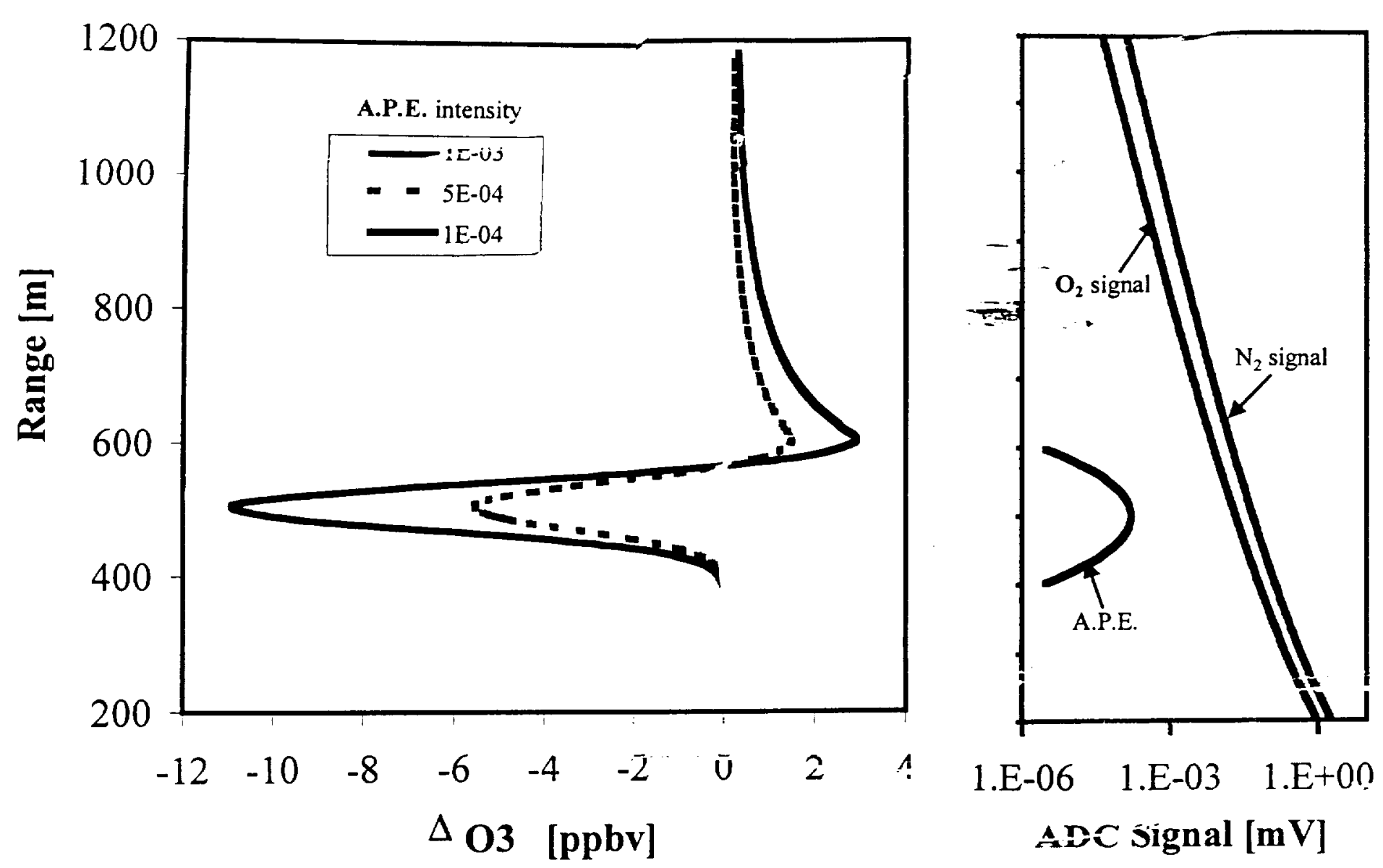

$\therefore$

Figure 5(a) 


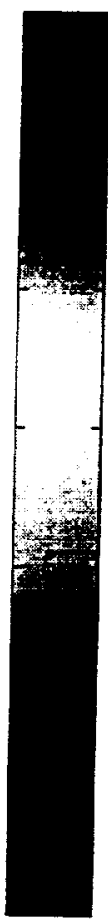

Figure 8 

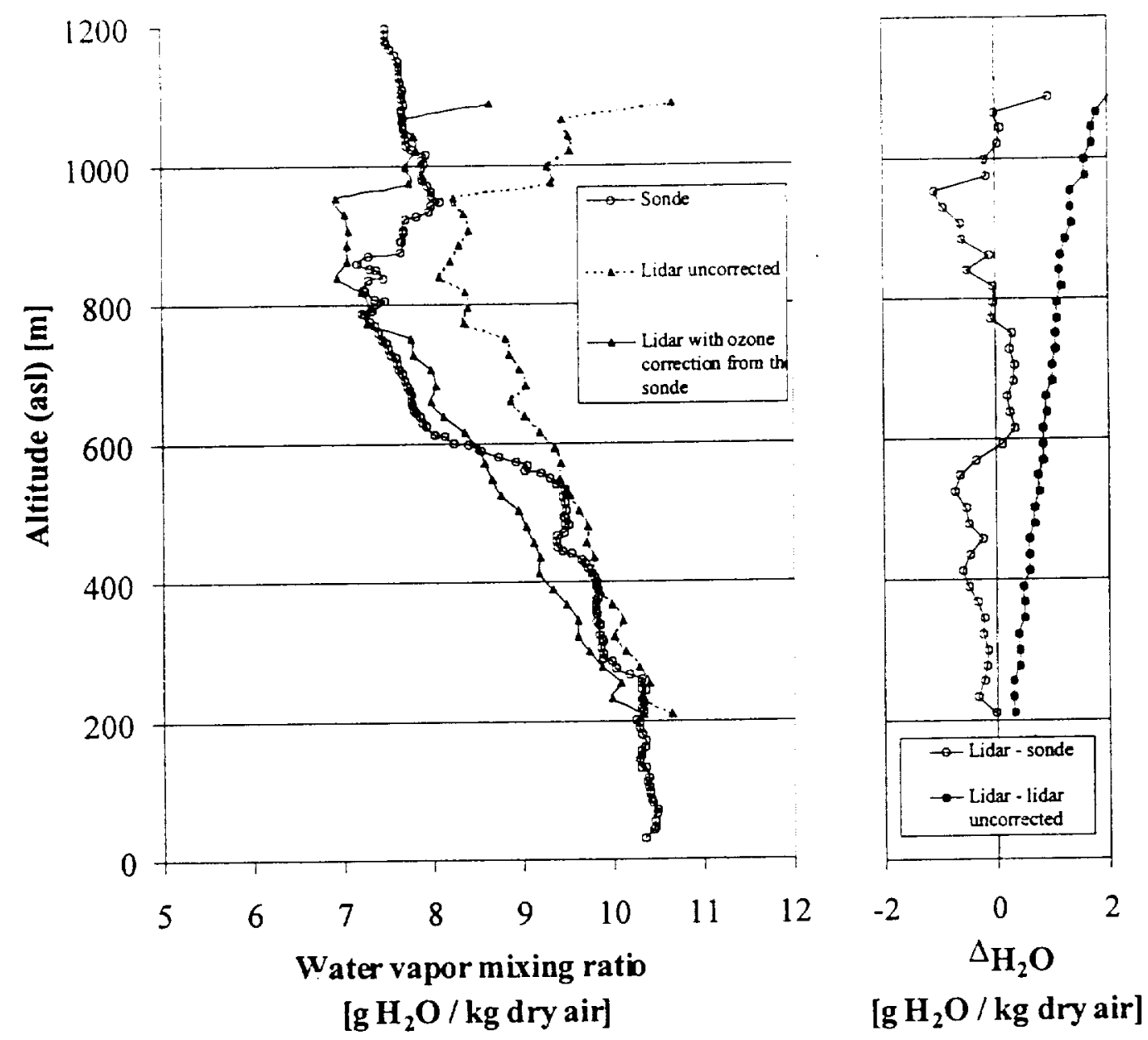

Figure 9 
$-$ 